\title{
The Integrin VLA-2 Binds Echovirus 1 and Extracellular Matrix Ligands by Different Mechanisms
}

\author{
Jeffrey M. Bergelson, ${ }^{\star}$ Bosco M. C. Chan, ${ }^{\star}$ Robert W. Finberg, ${ }^{\star}$ and Martin E. Hemler* \\ ${ }^{*}$ Laboratory of Infectious Disease, and ${ }^{\ddagger}$ Division of Tumor Virology, Dana-Farber Cancer Institute, \\ Harvard Medical School, Boston, Massachusetts 02115
}

\begin{abstract}
The integrin VLA-2 mediates cell adhesion to collagen and laminin and also functions as a virus receptor, mediating cell surface attachment and infection by a human pathogen, echovirus 1. To determine whether extracellular matrix proteins and virus interact with VLA-2 in the same manner, we carried out a detailed comparison of these two functions and found that they differed markedly in six different respects. In contrast to the ECM/VLA-2 interaction, echovirus 1 binding did not discriminate between functional forms of VLA-2, showed a different pattern of inhibition by anti- $\beta 1$ and $-\alpha 2$ antibodies, was not stimulated by phorbol esters, was not activated by $\beta 1$ antibodies that stimulate ECM binding, was not inhibited by any particular divalent cation, and most notably was not inhibited by EDTA. These striking differences were found both with intact cells expressing VLA-2 and with solubilized VLA-2, suggesting that VLA-2 interacts with these different ligands by markedly different mechanisms, and probably at different functional sites. In addition, alterations in the $\alpha 2$ cytoplasmic domain that had marked effects on cellular responses to collagen and laminin had no effect on virus internalization and cell killing. Thus VLA-2-mediated events that occur after receptor occupancy by extracellular matrix proteins also appear to be distinct from those that occur after receptor interaction with virus. (J. Clin. Invest. 1993. 92:232-239.) Key words: virus receptor • cell adhesion • integrin • divalent cations $\bullet$ collagen
\end{abstract}

\section{Introduction}

The integrin family of cell surface molecules is composed of 14 $\alpha$ subunits and $8 \beta$ subunits that pair noncovalently to form 20 different heterodimers, each with distinct ligand binding capabilities. Ligands for integrins include extracellular matrix components, members of the immunoglobulin family, and blood clotting and complement proteins (1-5). A variety of studies suggest that ligand binding involves domains in the $\mathrm{NH}_{2}$-terminal regions of both the integrin $\alpha$ and $\beta$ chains. Within the $\beta 3$ chain, ligand binding occurs in the vicinity of amino acids 100 200 (6-8), a region that contains sequences highly conserved in nearly all known $\beta$ subunits. Within the $\alpha$ chain, ligands

Address reprint requests to Jeffrey M. Bergelson, Jimmy Fund 409, Dana-Farber Cancer Institute, 44 Binney Street, Boston, MA 02115. Dr. Chan's present address is Department of Chemistry and Biochemistry, University of Guelph, Guelph, Ontario, NIG 2W1 Canada.

Received for publication 24 July 1992 and in revised form 5 February 1993.

J. Clin. Invest.

(C) The American Society for Clinical Investigation, Inc.

$0021-9738 / 93 / 07 / 232 / 08 \quad \$ 2.00$

Volume 92, July 1993, 232-239 bind in the region of 3-4 putative binding sites for divalent cations, which have the partial EF hand sequence motif DXDXDGXXD (9-11). All known integrin ligand binding events have been found to be inhibited by EDTA, consistent with an essential role for $\alpha$ chain cation sites.

On some cells (particularly leukocytes and platelets) integrin-mediated adhesion can be modulated by a process known as "inside out" signaling. Upon triggering of cells with a variety of agonists, including the phorbol ester PMA, a poorly characterized signal is generated, resulting in substantially increased cell adhesion (12-21). Also, monoclonal antibodies to $\beta 1$ (2226) $\beta 2$ (27), and $\beta 3$ (28) integrins have been found, which stimulate integrin-mediated adhesion by a mechanism probably distinct from phorbol ester stimulation (29).

Within the group of integrins that share the $\beta 1$ subunit (called VLA proteins), VLA-2 $(\alpha 2 \beta 1)$ often functions as an adhesion receptor mediating cell attachment to collagen and laminin (30-35). On some cell types, however, it acts strictly as a collagen receptor (33-36), and on at least one cell it did not bind to either collagen or laminin (2). As seen with other integrins, these VLA-2 adhesion functions are inhibited by EDTA, indicating a requirement for divalent cations. Notably, although VLA-2-mediated adhesion to collagen is promoted by $\mathrm{Mg}^{++}$and $\mathrm{Mn}^{++}$, it is inhibited in the presence of $\mathrm{Ca}^{++}(36$, 37). Also, like other integrin functions, VLA-2-mediated cell adhesion can be dramatically stimulated by certain antibodies to the $\beta 1$ subunit (24), and to a variable extent by PMA $(20,29)$.

Recently, VLA-2 was shown not only to be a receptor for extracellular matrix (ECM $)^{1}$ proteins, but also to mediate attachment and infection by echovirus 1 (38), a human picornavirus responsible for febrile illnesses and aseptic meningitis. While echovirus 1 has probably evolved to bind to VLA-2, it is not clear whether virus and ECM ligands share the same binding site(s) on the VLA-2 molecule. It is also not known whether the cytoplasmic tail of the $\alpha 2$ subunit has a role in events occurring after receptor-mediated virus binding, such as virus internalization, and subsequent killing of the host cell. For VLA-2-mediated binding to ECM ligands, alterations of the cytoplasmic tail of the $\alpha 2$ subunit have been found to have a critical role in subsequent events such as cell migration and collagen gel contraction (39).

To begin to answer these questions, we have analyzed six characteristic features of VLA-2 binding to ECM ligands and asked whether they also apply to virus binding. We have also substituted the cytoplasmic domain of $\alpha 2$ with domains from other $\alpha$ chains, and then compared these chimeras with respect to their ability to mediate virus binding and killing. The results show dramatic differences between ECM and virus binding to

1. Abbreviations used in this paper: ECM, extracellular matrix; FMDV, foot-and-mouth disease virus; PFU, plaque-forming unit. 
VLA- 2 in terms of the VLA-2 epitopes involved, cation requirements, regulation of adhesion, and the role of cytoplasmic domains in postbinding events.

\section{Methods}

Cell lines. K562 erythroleukemia cells were transfected with cDNA encoding the $\alpha 2$ subunit of VLA-2 in the $\mathrm{pFneo}$ expression vector to obtain K562-form 0 (binds neither collagen nor laminin) and K562form $\mathrm{C}$ (binds collagen only), or with the $\mathrm{pFneo}$ vector alone to obtain $\mathrm{KpF}$. Isolation and characterization of these cell lines (29) and the RDA2 cell line (40), which adheres to both collagen and laminin, have been described. RD cells transfected with chimeric $\alpha$ cDNA, containing the extracellular domains of $\alpha 2$ and the cytoplasmic domains of $\alpha 4$ (X2C4) or $\alpha 5$ (X2C5), have also been described (41).

Monoclonal antibodies. AA 10 (38), 5E8 (42), and 12F1 (43) recognize the $\alpha 2$ subunit of VLA-2. LiA 1/2 (24), DE9 (38), TS2/16 (44), mAb 13 (45), 4B4 (46), and A-1A5 (47) recognize the $\beta 1$ subunit. Two other VLA-2 specific antibodies, HAS3 and HAS4 (both murine IgG2a), were the gift of J. Adams and F. M. Watt. Control antibodies P3 (48) (murine IgG1 derived from MOPC 21), UPC10 (murine IgG2a plasmacytoma), W6/32 (49) (murine IgG2a, recognizing a monomorphic determinant of HLA-A,B,C (50), and 23A-5-21S (murine IgM, anti $\mathrm{H}-2 \mathrm{D}^{\mathrm{b}}$ ) were obtained from Sigma Immunochemicals (St. Louis, MO) or the American Type Culture Collection (Rockville, MD). Except for LiA $1 / 2$ (a hybridoma supernatant diluted 25-fold), antibodies used were ascites fluid diluted 100 -fold before use, purified antibody ( $12 \mathrm{~F} 1$ ) at $10 \mu \mathrm{g} / \mathrm{ml}$, or hybridoma supernatant (AA10) at 10 $\mu \mathrm{g} / \mathrm{ml}$. The same solution of each antibody was used for both cell attachment and virus binding assays.

Radiolabeled virus binding. Echovirus serotype 1 (American Type Culture Collection) was metabolically labeled by growth in medium containing $\left[{ }^{35} \mathrm{~S}\right]$ methionine, and purified by detergent treatment, pelleting, and sucrose gradient centrifugation, as described for poliovirus 2 (51). Cell suspensions $\left(\sim 5 \times 10^{5}\right.$ cells $)$ were incubated $30 \mathrm{~min}$ at room temperature in $100 \mu \mathrm{l}$ of medium or antibody as indicated; in some experiments, cells were then washed to remove unbound antibody, with no change in results. Except where indicated in the figure legends, radiolabeled virus $(\sim 20,000 \mathrm{cpm} ; 50-200$ plaque-forming unit [PFU] per cpm) was added in HBSS (GIBCO BRL, Gaithersburg, MD) buffered with $10 \mathrm{mM}$ Hepes $\mathrm{pH} 7.0$, and containing $20 \mathrm{mM}$ $\mathrm{MgCl}_{2}$ and $4 \%$ bovine calf serum. Incubation with gentle rocking proceeded for 30-60 min, after which cells were washed twice in the same buffer, dissolved in $0.5 \mathrm{ml}$ Solvable (New England Nuclear, Boston, MA), and cell-bound radioactivity was determined by scintillation counting.

Cell adhesion assays. Cell attachment to matrix proteins was determined as described (41). Briefly, cells were suspended in RPMI-5\% FCS at 3-5 $\times 10^{6} / \mathrm{ml}$, treated with $5 \mu \mathrm{g} / \mathrm{ml}\left(2^{\prime}, 7^{\prime}\right)$-bis(carboxyethyl)$(5,6)$-carboxyfluorescein (Molecular Probes, Inc., Eugene, OR) at $37^{\circ} \mathrm{C}$ for $30 \mathrm{~min}$, then washed twice in PBS. After incubation with monoclonal antibodies or buffer containing specific divalent cations, 5 $\times 10^{4}$ cells in $0.1 \mathrm{ml}$ were added to plastic tissue culture plates precoated with collagen or laminin. Adhesion was permitted to occur for $20 \mathrm{~min}$ at $37^{\circ} \mathrm{C}$, unattached cells were removed by gentle washing, and fluorescent cell adherence was determined using a 96-well fluorescence analyzer (IDEXX Co., Portland, ME), and normalized to wells containing 50,000 cells. Background values for cell adhesion to wells coated with $0.1 \%$ BSA were subtracted. All results are expressed as the mean number of cells bound per $\mathrm{mm}^{2}$ of surface area $( \pm \mathrm{SD})$ for triplicate determinations.

Interaction of virus and ECM proteins with isolated VLA-2. Receptor binding to collagen and laminin sepharose was performed as described (29). K562 cells transfected with $\alpha 2$ were surface labeled with ${ }^{125} \mathrm{I}$ using lactoperoxidase and solubilized in $0.1 \mathrm{M}$ octyl- $\beta$-D-thioglycopyranoside (OSPG; Calbiochem-Novabiochem Corp., La Jolla, CA), $0.1 \mathrm{M} n$-octyl- $\beta$-D-glucopyranoside (OPG, Sigma Chemicals), $0.1 \mathrm{mM}$
$\mathrm{MnCl}_{2}$ and protease inhibitors (PMSF, leupeptin, and aprotinin) in PBS for $1 \mathrm{~h}$ at $4^{\circ} \mathrm{C}$. Immunodepletion of background proteins from the cell lysate was achieved by incubation with $\mathrm{mAb} J 2 \mathrm{~A} 2$, followed by protein A-Sepharose. After the addition of various anti- $\alpha 2$ or anti- $\beta 1$ antibodies, cell lysates were incubated batchwise with $0.1 \mathrm{ml}$ of collagen-Sepharose beads $\left(18 \mathrm{~h}\right.$, at $\left.4^{\circ} \mathrm{C}\right)$. After washing with $8 \mathrm{ml}$ of wash buffer, specifically bound proteins were eluted using SDS-sample buffer, analyzed by SDS-PAGE, and quantitated using a densitometer (Quick Scan R\&D; Helena Laboratories, Beaumont, TX).

For virus binding to affinity-isolated VLA-2, cells were extracted with OPG/OSPG buffer (as above, except containing $\mathrm{MgCl}_{2}$ and $\mathrm{CaCl}_{2}$ in addition to $\mathrm{MnCl}_{2}$ ) for $1 \mathrm{~h}$ at $4^{\circ} \mathrm{C}$, then incubated with CL4B protein A-Sepharose beads (Pharmacia LKB Biotechnology, Piscataway, $\mathrm{NJ}$ ) precoated with mAb HAS-4 (murine IgG2a), or with isotypematched control antibodies UPC10 or W6/32. Beads were then washed with $0.025 \mathrm{M}$ OPG/0.025 M OSPG in PBS and incubated with radiolabeled virus $(20,000-50,000 \mathrm{cpm}$ in $0.2 \mathrm{ml}$ Hanks' $-10 \mathrm{mM}$ Hepes- $10 \mathrm{mM} \mathrm{MgCl} 2-4 \%$ bovine calf serum) for $4 \mathrm{~h}$ at room temperature. After further washing, bound radioactivity was determined by scintillation counting. For identification of radiolabeled proteins bound to antibody-coated beads, cell extracts from ${ }^{125} \mathrm{I}$-labeled HeLa cells were prepared as above and incubated with antibody-coated beads, then beads were washed as above and boiled in Laemmli sample buffer. Eluted proteins were then subjected to electrophoresis in a $10 \%$ polyacrylamide gel under reducing conditions and identified by autoradiography.

Virus infection. $10^{5} \mathrm{HeLa}$ cells were suspended in HBSS without calcium or magnesium (Whittaker M. A. Bioproducts, Walkersville, MD) containing $0.5 \%$ BSA (HBSS-BSA), or in HBSS-BSA containing $2 \mathrm{mM} \mathrm{MgCl}_{2}, 2 \mathrm{mM} \mathrm{MnCl}, 2 \mathrm{mM} \mathrm{CaCl}_{2}$, or $2 \mathrm{mM}$ EDTA. Virus was added ( 5 PFU per cell, diluted in HBSS-BSA) and allowed to adsorb for $30 \mathrm{~min}$ at room temperature. Unbound virus was removed by extensive washing, then cells were plated in $1 \mathrm{ml}$ Minimal Eagle's Medium with $5 \%$ bovine serum and incubated overnight. Cells were frozen and thawed to release virus, and virus titer determined by plaque assay on HeLa cells.

\section{Results}

Interaction of virus and ECM proteins with different functional forms of $V L A-2$. We have previously shown that $\alpha 2$-transfected RD cells express VLA- 2 that binds to both collagen and laminin (41), and thus is designated VLA-2 form CL. In contrast, $\alpha 2$-transfected K562 erythroleukemia cells (KA2 cells) expressed VLA-2 that adhered to collagen but not laminin (form $C$ ), or adhered neither to collagen nor to laminin (form 0 ) (29), as shown in Fig. $1 A$ and $B$. We previously showed that echovirus 1 bound to VLA-2 form CL on RD cells (38), and here we show that virus also bound to VLA-2 form $C$ and form 0 on KA2 cells (Fig. $1 C$ ). In a control experiment, echovirus 1 failed to bind to mock-transfected $(\mathrm{KpF})$ cells. Thus, virus binds to VLA-2-expressing cells that bind neither of the ECM proteins.

Epitopes on $\alpha 2$ and $\beta 1$ involved in virus binding and ECM attachment. To determine whether the same VLA-2 epitopes are important for attachment to extracellular matrix proteins and for virus binding, we carried out comparative monoclonal antibody inhibition experiments. Results obtained with antibodies to the $\beta 1$ subunit suggest that the binding sites for virus and collagen are not identical (Fig. 2). Both mAb 13 and LiA $1 / 2$ completely abolished RDA2 cell adhesion to collagen but had only weak or partial effects on virus binding. Antibodies A-1A5, TS2/16, and the control antibody P3 had little inhibitory effect on either collagen or virus binding. For comments 

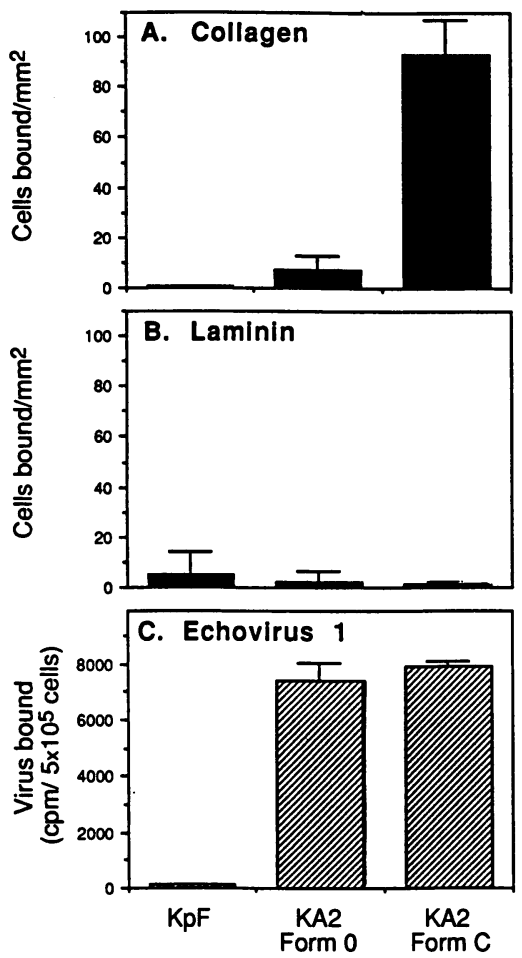

Figure 1. K562 transfectants expressing different functional forms of VLA-2: ECM attachment compared with radiolabeled virus binding. $(A)$ and $(B)$, Adhesion of mock-transfectants $(\mathrm{KpF})$ or $\alpha 2$ transfectants (K-form 0 and $\mathrm{K}$-form $\mathrm{C}$ ) to tissue culture wells coated with $(A)$ collagen $(2$ $\mu \mathrm{g} / \mathrm{ml})$ or $(B)$ laminin $(10 \mu \mathrm{g} / \mathrm{ml})$, expressed as cells bound $/ \mathrm{mm}^{2}$. $(C)$, Binding of $\left[{ }^{35}\right.$ S ] methionine labeled echovirus 1, expressed as cpm bound per 5 $\times 10^{5}$ cells. Standard deviations for triplicate samples are shown.

regarding TS2/16 stimulation of adhesion, see text pertaining to Fig. 5 below.

Anti- $\alpha 2$ antibodies also revealed a difference between ECM and virus binding (Fig. 3). The antibody $12 \mathrm{~F} 1$ had no effect on RDA2 cell adhesion to ECM proteins collagen and laminin $(A, B)$, but completely abrogated virus binding to RDA2 cells $(C)$ and to HeLa and KA2 cells (not shown). Two other antibodies, 5E8 and AA10, which inhibited cell attachment to collagen and laminin, gave complete inhibition of virus binding $(C)$. Additional anti-VLA-2 antibodies with no effect on ECM attachment (J. Adams and F. M. Watt, personal communication), had minimal effects (13-15\% inhibition) on radiolabeled virus binding to HeLa cells (not shown).

Effects of PMA and monoclonal antibodies on ECM attachment and virus binding. Like many integrin functions, VLA-2-
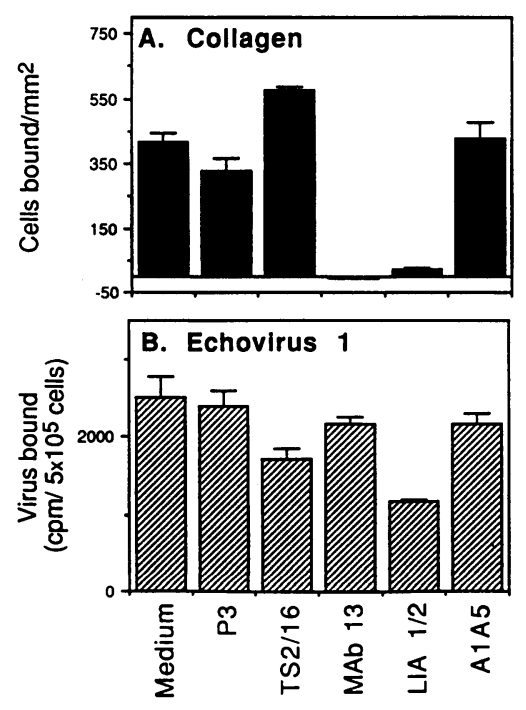

Figure 2. Effects of $\beta 1$ monoclonal antibodies on RDA2 cell adhesion to collagen and on radiolabeled virus binding. RDA2 cells were incubated with monoclonal antibodies (ascites fluids diluted $1 / 100$ ) then added to tissue culture wells coated with $(A)$ collagen $0.2 \mu \mathrm{g} / \mathrm{ml}$, or $(B)$ collagen $10 \mu \mathrm{g} / \mathrm{ml}$, or $(C)$ incubated with radiolabeled echovirus 1 , as described in Methods. $\mathrm{P} 3$ is an irrelevant murine monoclonal antibody.
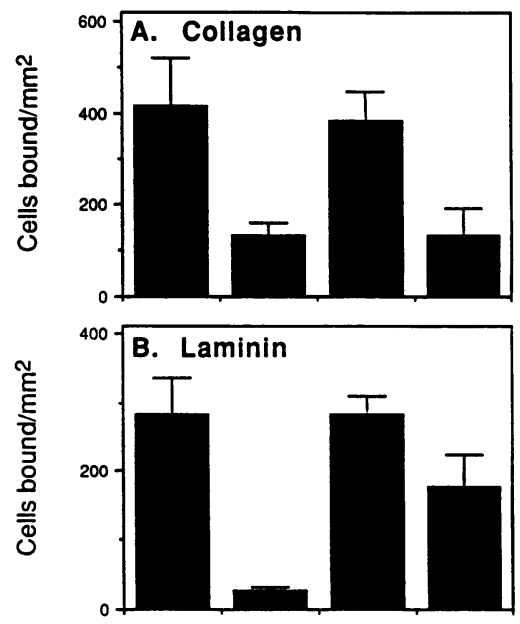

Figure 3. Effects of $\alpha 2$ monoclonal antibodies on RDA2 cell adhesion to collagen and laminin, and on radiolabeled virus binding. RDA2 cells were incubated

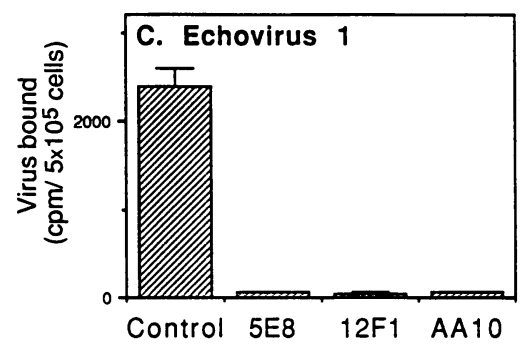
with monoclonal antibodies, then added to tissue culture wells coated with $(A)$ collagen $0.1 \mu \mathrm{g} / \mathrm{ml}$, or $(B)$ lami$\operatorname{nin} 3 \mu \mathrm{g} / \mathrm{ml}$, or $(C)$ incubated with radiolabeled echovirus 1 , as described in Methods.

mediated cell adhesion to collagen was stimulated by treatment with phorbol esters. Exposure to 50 nM PMA markedly increased the adhesion of KA2 cells with form $\mathrm{C}$ or form 0 VLA2 to collagen (Fig. $4 A$ ), but treatment with 50 nM PMA did not enhance the capacity of these cells to bind echovirus 1 (data not shown). No enhancement of echovirus binding was seen even when much higher concentrations of PMA were used ( 5 $\mu \mathrm{M}$, Fig. $4 \mathrm{~B}$ ). In similar experiments (not shown) PMA treatment did not increase virus binding by Jurkat $T$ cells, although PMA has been shown to stimulate VLA-2-mediated Jurkat cell adhesion to ECM proteins (21).

Whereas KA2 cells expressing VLA-2 form 0 showed almost no adhesion to collagen, treatment with the anti- $\beta 1 \mathrm{mAb}$ TS2/ 16 (but not with other anti- $\beta 1$ [ $\mathrm{mAb} 13, \mathrm{DE} 9$ ], anti- $\alpha 2$ [AA10], or control [P3] antibodies) dramatically induced adhesion to collagen (Fig. $5 \mathrm{~A}$ ). In contrast, binding of radiola-
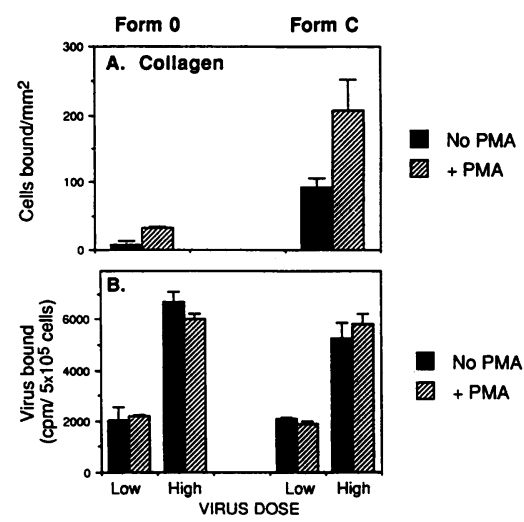
capacity to bind radiolabeled echovirus $1.5,000 \mathrm{cpm}$ of virus (low dose) or $20,000 \mathrm{cpm}$ (high dose) were added to $5 \times 10^{5}$ cells. 

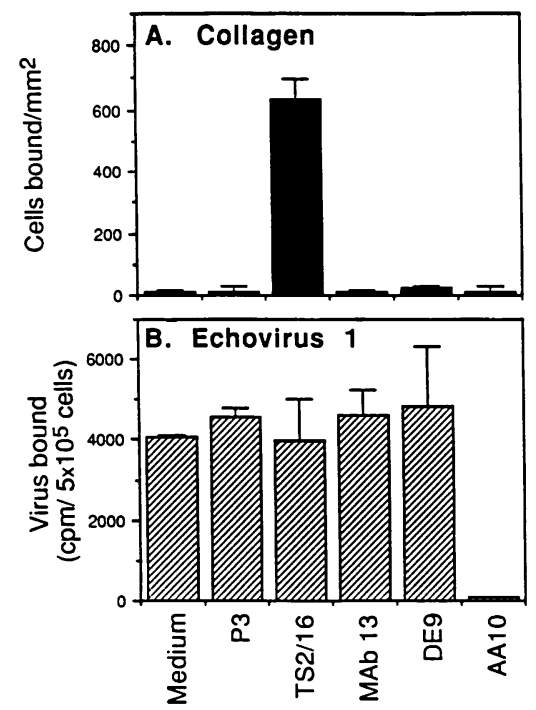

Figure 5. Activation of K562-form 0 by monoclonal antibody TS2/16: collagen attachment compared with radiolabeled virus binding. Cells were incubated with monoclonal antibodies or medium alone for $30 \mathrm{~min}$ at room temperature, then washed and assayed $(A)$ for adhesion to tissue culture wells coated with collagen $2 \mu \mathrm{g} / \mathrm{ml}$ or $(B)$ for capacity to bind radiolabeled echovirus 1. P3 is an irrelevant murine monoclonal antibody.

beled virus was not altered in the presence of TS2/16 or the other anti- $\beta 1$ antibodies (Fig. $5 \mathrm{~B}$ ); AA10, an anti- $\alpha 2 \mathrm{mAb}$, completely inhibited virus binding as seen previously (38) and in Fig. 3 above. Though less dramatic than in Fig. 5, TS2/16 stimulation of RDA2 cell adhesion to collagen was also seen in Fig. 2, especially at the lower collagen dose (Fig. $2 A$ ). In Fig. 2 $C$, as in Fig. $5 B$, TS2/16 had little effect on virus binding.

Cation requirements for $V L A-2$ mediated virus binding and adhesion to ECM proteins. Consistent with previously reported results for platelets $(36,52)$, VLA-2-mediated attachment of RDA2 cells to collagen was inhibited by EDTA and reconstituted by the addition of $2 \mathrm{mM}$ of either $\mathrm{Mg}^{++}$or $\mathrm{Mn}^{++}$but not $\mathrm{Ca}^{++}$(Fig. $6 \mathrm{~A}$ ). In contrast, substantial virus binding to RDA2 cells was observed either in the absence or presence of extracellular cations, or in the presence of $2 \mathrm{mM}$ EDTA (Fig. $6 B$ ). No virus binding was seen when cells were preincubated with the $\alpha 2$ monoclonal antibody AA10, confirming that binding was VLA-2 specific. Notably, virus binding not only occurred in
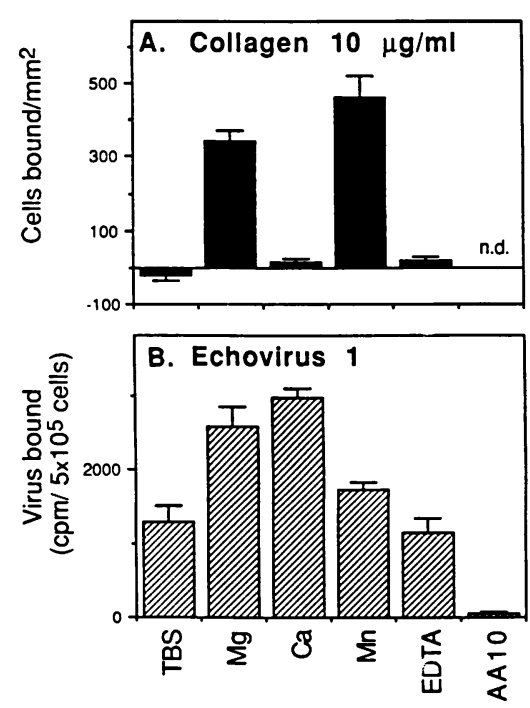

Figure 6. Effect of divalent cations on RDA2 cell adhesion to collagen, and on radiolabeled virus binding. RDA2 cells were washed in $1 \mathrm{mM}$ EDTA to remove extracellular divalent cations, then washed in PBS containing no calcium or magnesium. Cells were equilibrated $30 \mathrm{~min}$ in TBS-BSA-glucose containing $2 \mathrm{mM} \mathrm{MgCl}_{2}$, $2 \mathrm{mM} \mathrm{CaCl}_{2}, 2 \mathrm{mM}$ $\mathrm{MnCl}_{2}, 2 \mathrm{mM}$ EDTA, or monoclonal antibody $\mathrm{AA} 10$ as indicated, then $(A)$ added to tissue culture wells coated with

collagen $10 \mu \mathrm{g} / \mathrm{ml}$, or $(B)$ incubated with radiolabeled echovirus 1 . Virus was dialyzed against TBS-BSA-glucose before use in this experiment.
Table I. Virus Production by HeLa Cells Infected in the Presence of EDTA or Divalent Cations

\begin{tabular}{ccccc}
\hline No cations & $\mathrm{Mg}$ & $\mathrm{Ca}$ & $\mathrm{Mn}$ & EDTA \\
\hline $3.0 \times 10^{6}$ & $8 \times 10^{6}$ & $1.4 \times 10^{7}$ & $4.0 \times 10^{6}$ & $3.3 \times 10^{6}$
\end{tabular}

HeLa cells were exposed to virus (5 PFU per cell) in buffer with or without divalent cations, washed and incubated overnight, and virus titer measured as described in Methods. Table shows averaged virus yields (PFU/ml) for duplicate cultures.

the presence of $\mathrm{Ca}^{++}$, but consistently exceeded binding observed in the presence of $\mathrm{Mg}^{++}$for RDA2 cells (Fig. $6 \mathrm{~B}$ ), as well as HeLa cells and $\alpha 2$-transfected K562 cells (not shown). Virus binding to HeLa and K562 cells was only marginally inhibited by EDTA (not shown). As shown in Table I, virus infection as well as binding could occur in the presence of EDTA. Quite similar amounts of virus were produced by HeLa cells infected in the presence or absence of divalent cations.

Interactions of solubilized VLA-2 with virus and with collagen. To determine whether the differences between VLA-2mediated virus binding and cell adhesion observed in the preceding experiments reflected direct interaction of VLA-2 with ligands or were the end result of more complex cellular processes, we examined the interaction of solubilized VLA-2 with virus and collagen. Previous studies have shown close parallels between VLA-2-mediated cell adhesion and direct interaction of VLA-2 with collagen and laminin. In particular, interaction of solubilized and / or purified VLA-2 with its extracellular matrix ligands is inhibited by EDTA $(33,36,37)$, by $\mathrm{Ca}^{++}(36$, 37 ), or by specific monoclonal antibodies (36). In addition, different functional forms of VLA-2, isolated from specific cell types $(33,34)$ bind directly to ligands with the same specificity as the cells from which they were derived. As shown in Table II (and in similar experiments described elsewhere [29]), detergent-solubilized VLA-2 from $\alpha 2$-transfected K 562 cells bound at only a low to moderate level to collagen-Sepharose at $4^{\circ} \mathrm{C}$. However, in the presence of the anti- $\beta 1 \mathrm{mAb}$ TS2/16, adhesion of soluble VLA-2 to collagen was enhanced approximately

Table II. Effect of anti- $\alpha 2$ and anti- $\beta 1$ Antibodies on Binding of Soluble VLA-2 to Collagen-Sepharose

\begin{tabular}{lcc}
\hline & \multicolumn{2}{c}{ VLA-2 bound to collagen-Sepharose } \\
\cline { 2 - 3 } \multicolumn{1}{c}{ mAb added } & Experiment 1 & Experiment 2 \\
\hline J-2A2 (control) & 14.7 & - \\
12F1 (anti- $\alpha 2)$ & 19.5 & 13.2 \\
TS2/16 (anti- $\beta 1)$ & 56.8 & 42.3 \\
4B4 (anti- $\beta 1)$ & 1.4 & 1.3 \\
\hline
\end{tabular}

Lysates from two different $\alpha 2$-transfected K562 cell lines were prepared as described in Methods, and then incubated with collagen-Sepharose in the presence of the indicated antibodies. Bound VLA-2 subunits ( $\alpha 2$ plus $\beta 1$ ) were quantitated by densitometry, and the results (in arbitrary units) are reported for each experiment. In the presence of TS2/16, the amount of VLA-2 bound was typically $>50 \%$ of the total VLA- 2 added. 
hanced approximately threefold. In contrast, the anti- $\alpha 2 \mathrm{mAb}$ $12 \mathrm{~F} 1$ (shown above to inhibit cell attachment to virus but not to ECM) failed to stimulate or inhibit VLA-2 binding to collagen. Another anti- $\beta 1$ antibody, called $4 B 4$, had a marked inhibitory effect on the binding of soluble VLA-2 to collagen. $4 \mathrm{~B} 4$ binds to the same epitope as most other anti- $\beta 1 \mathrm{mAb}$ (including $\mathrm{mAb} 13$ and $\mathrm{LiA} 1 / 2$ ) that inhibit $\beta 1 / \mathrm{ECM}$ adhesion functions (results not shown). In a control experiment using untransfected K562 lysate, no binding of VLA-2 to collagen-Sepharose was observed. These results, together with those of others, support the conclusion that VLA-2-dependent cell adhesion to collagen and laminin reflects the direct interaction of VLA-2 with these ligands.

In a similar way, we found that virus interacted directly with VLA- 2 in a cellfree environment and that virus binding to isolated VLA-2 closely resembled binding to intact cells. These experiments made use of an anti-VLA-2 monoclonal antibody, HAS-4, which did not prevent virus attachment to cells and thus is likely to recognize an epitope distinct from the virus binding site. We isolated VLA-2 from detergent extracts of
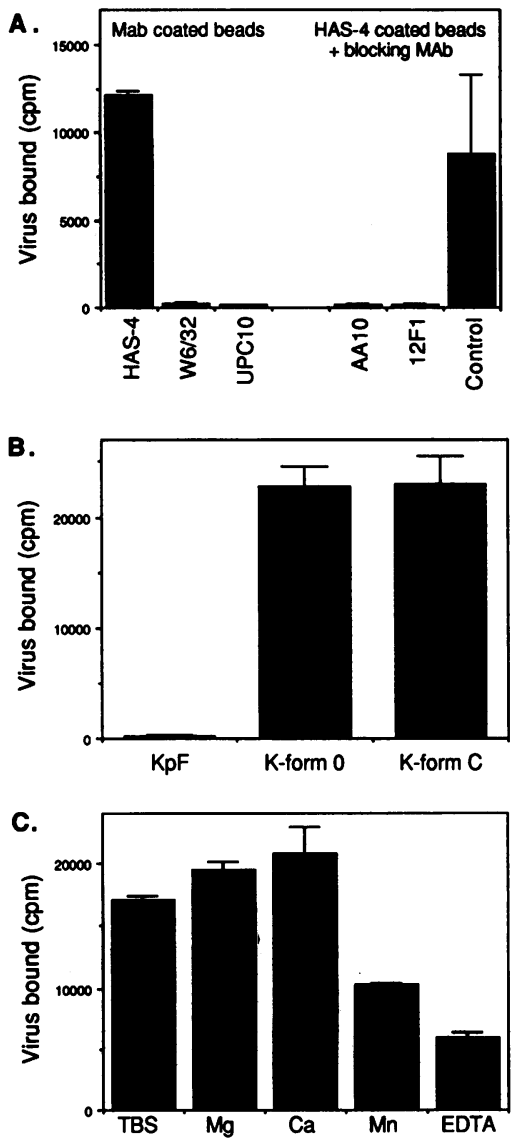

Figure 7. Virus attachment to VLA-2 isolated on beads. Detergent extracts of HeLa cells or K562A2 transfectants were incubated with CL4B protein A sepharose beads precoated with an anti-VLA-2 monoclonal antibody or isotype matched control antibodies, then beads were washed and exposed to $\left[{ }^{35} \mathrm{~S}\right] \mathrm{meth}-$ ionine labeled echovirus 1 , all as described in Methods. After 4-h incubation at room temperature, beads were washed extensively and bound virus determined by scintillation counting. Results are expressed as cpm bound/ $5 \times 10^{6}$ cell equivalents. ( $A$, left side) HeLa cell extracts incubated with HAS- 4 coated beads or beads coated with control antibodies, $\mathrm{W} 6 / 32$ or UPC10. $(A$, right side) HAS-4 coated beads incubated with

HeLa cell extracts, washed, then further treated with anti- $\alpha 2 \mathrm{mAb}$ AA10 or $12 \mathrm{~F} 1$, or with a control antibody (23A-5-21S; anti-H-2 $\mathrm{D}^{\mathrm{b}}$ ). (B) Extracts of K562 $\alpha 2$ transfectants: KpF (mock transfectant), $\mathrm{K}$-form 0 , and $\mathrm{K}$-form $\mathrm{C}$. (C) Effect of divalent cations. HeLa cell extracts were incubated with HAS-4-coated beads, beads were washed in TBS (no cations), then virus was added in TBS-BSA-glucose alone, or in buffer supplemented with $2 \mathrm{mM} \mathrm{Mg}, \mathrm{Ca}, \mathrm{Mn}$, or EDTA. The relatively high binding in TBS may reflect the fact that in this experiment, VLA-2 coated beads were not pretreated with EDTA to remove associated cations before washing and addition of virus.

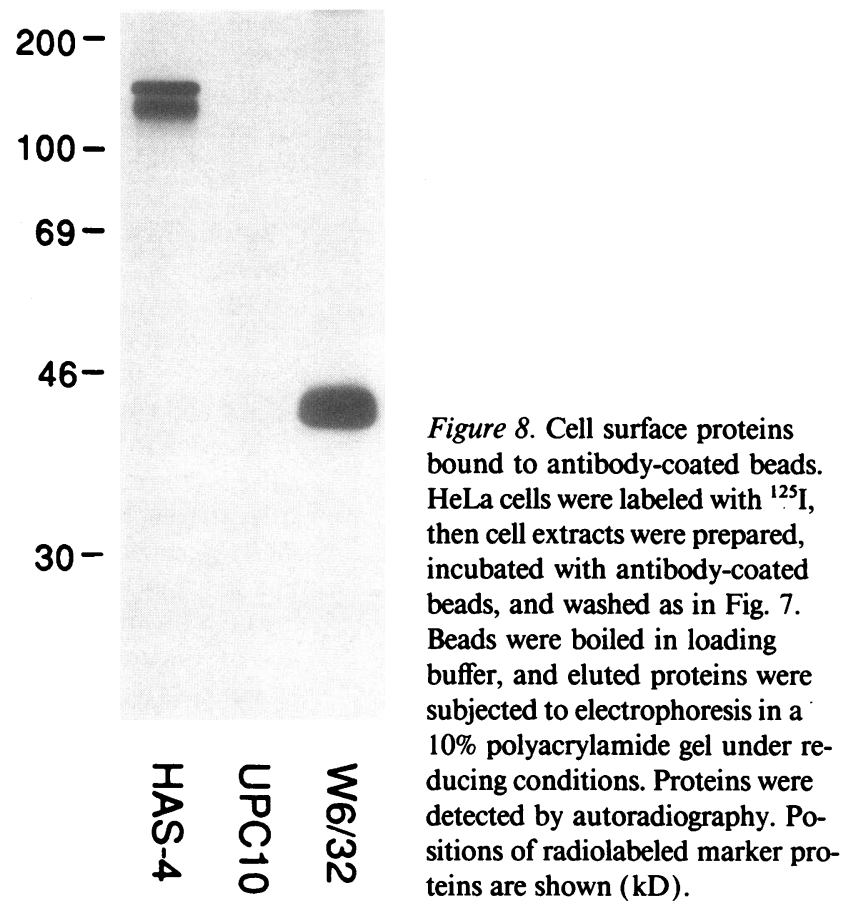

HeLa or KA2 transfectants using HAS-4-coated protein A Sepharose beads and measured the attachment of radiolabeled virus to receptor protein (Fig. 7). Virus bound specifically to beads coated with VLA-2 (Fig. $7 A$ ); no binding was observed to beads coated with isotype-matched control antibodies and exposed to the same cell extracts. In experiments with extracts from iodinated HeLa cells, HAS-4-coated beads bound specifically the $\alpha$ and $\beta$ subunits of VLA-2 (Fig. 8).

Virus attachment to isolated VLA-2 was specifically prevented by the anti- $\alpha 2$ monoclonal antibody AA10, and also by 12F1 (Fig. $7 \mathrm{~A}$ ), which prevented virus attachment to cells, but not cell attachment or VLA-2 binding to extracellular matrix proteins (Fig. 3 and Table II). Virus bound equally well to VLA-2 isolated from KA2 (form 0 ) and KA2 (form C) transfectants, but did not bind to HAS-4-coated beads exposed to cell extracts from mock-transfected K562 cells, which do not express VLA-2 (Fig. 7 B). Finally, as determined for virus attachment to intact cells, virus binding to isolated VLA-2 was not suppressed in the presence of calcium, was not stimulated by manganese, and occurred even in the presence of $2 \mathrm{mM}$ EDTA (Fig. $7 C$ ).

Post-ligand binding events. Previously generated chimeric forms of the $\alpha 2$ subunit (called X2C4 and X2C5) contained cytoplasmic domains from integrin $\alpha 4$ and $\alpha 5$ subunits respectively (39). When these chimeric $\alpha 2$ molecules and wild type $\alpha 2($ RDA2 $=\mathrm{X} 2 \mathrm{C} 2)$ were transfected into RD cells, adhesion to collagen and laminin was essentially indistinguishable, but post-ligand binding events such as cell migration and collagen gel contraction were dramatically altered (39). When tested for echovirus 1 binding, RDA2 (X2C2), RD-X2C4, and RD$\mathrm{X} 2 \mathrm{C} 5$ cells all bound virus equally well ( Table III). In a test of susceptibility to infection, all these cell lines were killed within $24 \mathrm{~h}$ when infected with virus at either 0.5 or 0.05 PFU per cell; in contrast, mock-transfected $\mathrm{RDpF}$ cells, which express little or no VLA-2, showed no evidence of cytopathic effect even after $48 \mathrm{~h}$ (Table III). This experiment indicated that the $\alpha 2$ 
Table III. Effects of Cytoplasmic Tail Substitutions on Virus Binding and Infection

\begin{tabular}{lcccc}
\hline & RDpF & RD-X2C2 & RD-X2C4 & RD-X2C5 \\
\hline $\begin{array}{l}\text { VLA-2 } \\
\text { expression } \\
\text { (MCF) }\end{array}$ & 7 & 84 & 82 & 150 \\
$\begin{array}{l}\text { Virus bound } \\
\text { (cpm) }\end{array}$ & $198 \pm 21$ & $6,952 \pm 48$ & $7,952 \pm 400$ & $13,657 \pm 546$ \\
$\begin{array}{l}\text { CPE at } 16 \mathrm{~h} \\
(\mathrm{MOI}=0.05)\end{array}$ & 0 & +++ & ++++ & ++++ \\
$\begin{array}{l}\text { CPE at } 44 \mathrm{~h} \\
(\mathrm{MOI}=0.5)\end{array}$ & 0 & ++++ & ++++ & ++++ \\
\hline
\end{tabular}

Relative cell surface expression of VLA-2 was determined by indirect immunofluorescence using mAb AA10 and a FITC-labeled goat anti-mouse Ig second antibody. MCF is the mean cell fluorescence (on a linear scale) determined for each cell line stained with $\mathrm{mAb}$ AA 10, minus the mean cell fluorescence of the same cells stained with an isotype matched negative control antibody. Binding of radiolabeled echovirus 1 was determined as in Methods and is expressed as cpm bound per $5 \times 10^{5}$ cells \pm SD for triplicate samples. For evaluation of cytopathic effect (CPE), $2 \times 10^{5}$ cells of each type were plated in 24 well plates and allowed to adhere overnight, then washed and exposed for $1 \mathrm{~h}$ to virus (either 0.5 or 0.05 PFU per cell) at room temperature. After washing to remove unbound virus, monolayers were fed and incubated at $37^{\circ} \mathrm{C}$. Cultures were observed daily for appearance of cytopathic effect, detected as cell rounding or detachment from the culture plate, or cell death. 0 indicates no visible difference between infected and uninfected control cells. +++ indicates $\geq 80 \%$ of cells rounded or dead. ++++ indicates $100 \%$ of cells dead.

cytoplasmic domain was not specifically required for events in virus infection leading to host cell death.

\section{Discussion}

In this paper and in previous papers, VLA-2-mediated adhesion to ECM ligands has been characterized in terms of celltype specific differences in function, important $\beta 1$ and $\alpha 2$ subunit epitopes, phorbol ester activation, anti- $\beta 1 \mathrm{mAb}$ stimulation, EDTA inhibition, and the relative effectiveness of $\mathrm{Mg}^{++}$ compared with $\mathrm{Ca}^{++}$. In every one of these six aspects, we have found that virus binding to VLA-2 is markedly different from ECM binding.

We have measured the interaction of both cellular and solubilized VLA-2 with both viral and ECM ligands. Consistent with our own and others' experience, VLA-2-mediated cell adhesion to ECM proteins closely paralleled the binding of VLA-2 to ECM proteins observed in cellfree systems. Similarly, we found that the important characteristics of virus attachment to cells are reproduced in assays using isolated VLA2. Thus, at the molecular as well as the cellular level, VLA-2 interacts quite differently with virus and ECM ligands.

The identification of VLA-2 as a receptor for echovirus 1 was based on the demonstration that anti- $\alpha 2$ monoclonal antibodies block virus binding and infection, and that RD cells deficient in $\alpha 2$ expression gain capacity to bind virus and become infected when transfected with cDNA encoding $\alpha 2$ (38).
In this report we describe another VLA-2 negative cell line, $\mathrm{K} 562$, that binds virus after transfection with $\alpha 2$ cDNA. Furthermore, the demonstration that virus bound directly to VLA2 isolated on beads provides novel confirmatory evidence for the direct role of this protein in virus attachment.

VLA-2 interactions with virus and ECM proteins occur by quite different mechanisms and can be regulated independently. Whatever structural features permit different functional forms of VLA-2 to bind differentially to ECM proteins, they are not recognized by virus. In every cell analyzed, VLA-2 was constitutively active with respect to virus binding, and addition of PMA or TS2 / 16 caused no further increase in binding. To stimulate cell adhesion to collagen and laminin, phorbol esters probably trigger intracellular signaling and/or cytoskeletal interaction pathways, whereas mAb TS2/16 apparently induces a favorable conformational change in the $\beta 1$ subunit (29). Regardless of the precise details for these two distinct mechanisms for regulating cell adhesion to ECM proteins, we have found that neither is relevant to virus binding.

Although some anti- $\beta 1$ antibodies strongly blocked VLA2 -mediated adhesion to ECM, no anti- $\beta 1$ antibody has yet shown strong blocking of virus binding. These results suggest that virus may primarily interact with the $\alpha 2$ subunit. Some anti- $\alpha 2$ antibodies were found to block both ECM and virus binding, but it appears that echovirus 1 may utilize additional contact sites, not critical for ECM binding. Experiments in progress are aimed at mapping virus and ligand binding sites to determine their precise locations.

The observation that echovirus binding and subsequent cell infection were not substantially inhibited by EDTA may provide the best evidence that echovirus is a highly atypical ligand for an integrin. In contrast, binding and subsequent cell adhesion triggered by all other known integrin ligands (including ECM, serum and complement proteins, and members of the immunoglobulin superfamily) are completely inhibited in the presence of EDTA. Consistent with the relatively minimal effect of cations on virus binding, $\mathrm{Ca}^{++}$failed to inhibit virus binding, again in marked contrast to its strong negative effect on VLA-2-mediated adhesion to $\operatorname{ECM}(36,37)$.

It has been proposed that aspartate residues within ligands bind directly to EF-hand cations within integrins, thus supplying a missing coordination group $(7,53,54)$. This obviously cannot be the case for echovirus binding, which occurs in the absence of divalent cations. Thus, whereas VLA-2 binding to collagen may be through recognition of a KDGEA sequence (55), a defined triple helical region (56), or, perhaps, for some cell types, a sterically constrained RGD-containing sequence (57), we predict that VLA-2 is unlikely to recognize such domains on the surface of echovirus 1 .

We found that virus-induced cytopathic effect (and thus virus uptake) was not noticeably influenced by exchange of $\alpha 2$ subunit cytoplasmic domains. In contrast, collagen-mediated cell migration and collagen gel contraction are markedly dependent on particular $\alpha 2$ subunit cytoplasmic domain substitutions (39). Thus, although detailed mechanisms for virus internalization and cell killing remain to be determined, we hypothesize that these post-ligand binding mechanisms are quite distinct from those involved in cell migration and collagen gel contraction.

Two other picornaviruses, foot-and-mouth disease virus (FMDV) (58) and coxsackievirus A9 (59), may also bind to integrins, although this has not been definitively established. 
Those viruses are believed to bind susceptible cells by means of an RGD-containing peptide, which in the case of FMDV is known to protrude from the virus surface $(60)$. Given that RGD peptides are prototypical ligands for several integrins and also display strong cation dependence, we predict that FMDV and coxsackievirus A9 will not share the atypical binding properties of echovirus 1.

In conclusion, we have found that VLA-2 binding to echovirus 1 is strikingly different from ECM binding in every aspect analyzed, thus underscoring that the same receptor serves markedly different functions for parasite and host. A practical consequence of these results is that eventual therapeutic interventions could be aimed at inhibition of echovirus 1 binding without disturbing normal VLA-2 function.

\section{Acknowledgments}

We thank Drs. Susan Yamada, Richard Bankert, Francisco SanchezMadrid, Josephine Adams, Fiona Watt, and Virgil Woods for gifts of monoclonal antibodies, and Paul Kassner for help with adhesion assays.

This work was supported by National Institutes of Health grants AI289691 and AI31628, and a grant from the American Heart Association, 92013820, to R. W. Finberg, National Institutes of Health grant CA42368 to M. E. Hemler and a Centennial Fellowship from the Medical Research Council of Canada to B. M. C. Chan.

\section{References}

1. Hynes, R. O. 1992. Integrins: versatility, modulation and signalling in cell adhesion. Cell. 69:11-22.

2. Hemler, M. E., M. J. Elices, B. M. C. Chan, B. R. Zetter, N. Matsuura, and Y. Takada. 1990. Multiple ligand binding functions for VLA-2 ( $\alpha 2 \beta 1)$ and VLA$3(\alpha 3 \beta 1)$ in the integrin family. Cell Differ. Devel. 32:229-238.

3. Hemler, M. E. Structures and functions of VLA proteins and related integrins. 1991. In Receptors for Extracellular Matrix Proteins. R. P. Mecham and J. A. McDonald, editors. Academic Press, San Diego, CA. 255-259.

4. Albelda, S. M., and C. A. Buck. 1990. Integrins and other cell adhesion molecules. FASEB (Fed. Am. Soc. Exp. Biol.) J. 4:2868-2880.

5. Springer, T. A. 1990. Adhesion receptors of the immune system. Nature (Lond.). 346:425-434.

6. Smith, D. W., and D. A. Cheresh. 1988. The Arg-Gly-Asp binding domain of the vitronectin receptor: photoaffinity cross-linking implicates amino acid residues 61-203 of the $\beta$ subunit. J. Biol. Chem. 263:18726-18731.

7. Loftus, J. C., T. E. O'Toole, E. F. Plow, A. Glas, A. L. Frelinger, and M. H. Ginsberg. 1990. A $\beta 3$ integrin mutation abolishes ligand binding and alters divalent cation-dependent conformation. Science (Wash. DC). 249:915-918.

8. Charo, I. F., L. Nannizzi, D. R. Phillips, M. A. Hsu, and R. M. Scarborough. 1991. Inhibition of fibrinogen binding to GP IIb-IIla by a GP IIIa peptide. J. Biol. Chem. 266:1415-1421.

9. D'Souza, S. A., M. H. Ginsberg, T. A. Burke, and E. F. Plow. 1990. The ligand binding site of the platelet integrin receptor GPIIb-IIla is proximal to the second calcium binding domain of its $\alpha$ subunit. J. Biol. Chem. 265:3440-3446.

10. Smith, J. W., and D. A. Cheresh. 1990. Integrin ( $\alpha$ V $\beta 3$ )-ligand interaction: Identification of a heterodimeric RGD binding site on the vitronectin receptor. J. Biol. Chem. 265:2168-2172.

11. D'Souza, S. E., M. H. Ginsberg, G. R. Matsueda, and E. F. Plow. 1991. A discrete sequence in a platelet integrin is involved in ligand recognition. Nature (Lond.). 350:66-68.

12. Patarroyo, M., P. G. Beatty, J. W. Fabre, and C. G. Gahmberg. 1985. Identification of a cell surface protein complex mediating phorbol ester-induced adhesion (binding) among human mononuclear leukocytes. Scand. J. Immunol. 22:171-182.

13. Danilov, Y. N., and R. L. Juliano. 1989. Phorbol ester modulation of integrin-mediated cell adhesion: a postreceptor event. J. Cell Biol. 108:19251933.

14. Dustin, M. L., and T. A. Springer. 1989. T-cell receptor crosslinking transiently stimulates adhesiveness through LFA-1. Nature (Lond.). 341:619624.

15. Shimizu, Y., G. A. V. Seeventer, K. J. Horgan, and S. Shaw. 1990. Regulated expression and binding of three VLA $(\beta 1)$ integrin receptors on T cells. Nature (Lond.). 345:250-253.

16. Van Kooyk, Y., P. V. D.-V. Kemenade, P. Weder, T. W. Kuijpers, and
C. G. Figdor. 1989. Enhancement of LFA-1-mediated cell adhesion by triggering through CD2 or CD3 on T lymphocytes. Nature (Lond.). 342:811-813.

17. Wright, S. D., and B. C. Meyer. 1986. Phorbol esters cause sequential activation and deactivation of complement receptors on polymorphonuclear leukocytes. J. Immunol. 136:1759-1764.

18. Marguerie, G. A., E. F. Plow, and T. S. Edgington. 1979. Human platelets possess an inducible and saturable receptor for fibrinogen. J. Biol. Chem. 254:5357-5363.

19. Bennett, J. S., and G. Vilaire. 1979. Exposure of platelet fibrinogen receptors by ADP and epinephrine. J. Clin. Invest. 64:1393-1401.

20. Wilkins, J. A., D. Stupack, S. Stewart, and S. Caixia. 1991. $\beta 1$ integrin-mediated lymphocyte adherence to extracellular matrix is enhanced by phorbol ester treatment. Eur. J. Immunol. 21:517-522.

21. Chan, B. M. C., J. Wong, A. Rao, and M. E. Hemler. 1991. T cell receptor dependent, antigen-specific stimulation of a murine $T$ cell clone induces a transient, VLA protein-mediated binding to extracellular matrix. J. Immunol. 147:398-404.

22. Wayner, E. A., and N. L. Kovach. 1992. Activation dependent recognition by hematopoietic cells of the LDV sequence in the $\mathrm{V}$ region of fibronectin. $J$. Cell Biol. 116:489-497.

23. Kovach, N. L., T. M. Carlos, E. Yee, and J. M. Harlan. 1992. A monoclonal antibody to $\beta 1$ integrin (CD 29) stimulates VLA-dependent adherence of leukocytes to human umbilical vein endothelial cells and matrix components. $J$. Cell Biol. 116:499-509.

24. Arroyo, A. G., P. Sanchez-Mateos, M. R. Campanero, I. Martin-Padura, E. Dejana, and F. Sanchez-Madrid. 1992. Regulation of the VLA integrin-ligand interactions through the $\beta 1$ subunit. J. Cell Biol. 117:659-670.

25. Neugebauer, K. M., and L. F. Reichardt. 1991. Cell-surface regulation of $\beta 1$ integrin activity on developing retinal neurons. Nature (Lond.). 350:68-71.

26. Van de Wiel-van Kemenade, E., Y. V. Kooyk, A. J. de Boer, R. J. F. Huijbens, P. Weder, W. van de Kasteele, C. J. M. Melief, and C. G. Figdor. 1992. Adhesion of $\mathrm{T}$ and $\mathrm{B}$ lymphocytes to extracellular matrix and endothelial cells can be regulated through the $\beta$ subunit of VLA. J. Cell Biol. 117:461-470.

27. Robinson, M. K., D. Andrew, H. Rosen, D. Brown, S. Ortlepp, P. Stephens, and E. C. Butcher. 1992. Antibody against the Leu-CAM $\beta$-chain (CD 18) promotes both LFA-1 and CR3-dependent adhesion events. J. Immunol. 148:1080-1085.

28. O'Toole, T. E., J. C. Loftus, X. Du, A. A. Glass, Z. M. Ruggeri, S. J. Shattil, E. F. Plow, and M. H. Ginsberg. 1990. Affinity modulation of the allb $\beta 3$ integrìn (platelet GPIIb-IIIa) is an intrinsic property of the receptor. Cell. Regul. 1:883-893.

29. Chan, B. M. C., and M. E. Hemler. 1993. Multiple functional forms of the integrin VLA- 2 can be derived from a single $\alpha 2$ cDNA clone. Interconversion of forms induced by an anti- $\beta 1$ antibody. J. Cell Biol. 120:537-543.

30. Wayner, E. A., and W. G. Carter. 1987. Identification of multiple cell adhesion receptors for collagen and fibronectin in human fibrosarcoma cells possessing unique $\alpha$ and common $\beta$ subunits. J. Cell Biol. 105:1873-1884.

31. Takada, Y., E. S. Wayner, W. G. Carter, and M. E. Hemler. 1988. The extracellular matrix receptors, ECMRII and ECMRI, for collagen and fibronectin correspond to VLA-2 and VLA-3 in the VLA family of heterodimers. J. Cell. Biochem. 37:385-393.

32. Kramer, R., and N. Marks. 1989. Identification of integrin collagen receptors on human melanoma cells. J. Biol. Chem. 264:4684-4688.

33. Elices, M. J., and M. E. Hemler. 1989. The human integrin VLA-2 is a collagen receptor on some cells and a collagen-laminin receptor on others. Proc. Natl. Acad. Sci. USA. 86:9906-9910.

34. Kirchhofer, D., L. R. Languino, E. Ruoslahti, and M. D. Pierschbacher. 1990. Alpha-2/beta-1 integrins from different cell types show different binding specificities. J. Biol. Chem. 265:615-618.

35. Languino, L. R., K. R. Gehlsen, E. Wayner, W. G. Carter, E. Engvall, and E. Ruoslahti. 1989. Endothelial cells use $\alpha 2 \beta 1$ integrin as a laminin receptor. $J$. Cell Biol. 109:2455-2462.

36. Staatz, W., S. M. Rajpara, E. A. Wayner, W. G. Carter, and S. A. Santoro. 1989. The membrane glycoprotein Ia-IIa (VLA-2) complex mediates the Mg++dependent adhesion of platelets to collagen. J. Cell Biol. 108:1917-1924.

37. Grzesiak, J. J., G. E. Davis, D. Kirchhofer, and M. D. Pierschbacher. 1992. Regulation of $\alpha 2 \beta 1$-mediated fibroblast migration on type I collagen by shifts in the concentrations of extracellular $\mathrm{Mg} 2+$ and $\mathrm{Ca} 2+$. J. Cell Biol. 117:1109-1117.

38. Bergelson, J. M., M. P. Shepley, B. M. C. Chan, M. E. Hemler, and R. W. Finberg. 1992. Identification of the integrin VLA-2 as a receptor for echovirus 1. Science (Wash. DC). 255:1718-1720.

39. Chan, B. M. C., P. D. Kassner, J. A. Schiro, H. R. Byers, T. S. Kupper, and M. E. Hemler. 1992. Distinct cellular functions mediated by different VLA integrin $\alpha$ subunit cytoplasmic domains. Cell. 68:1051-1060.

40. Chan, B. M. C., N. Matsuura, Y. Takada, B. R. Zetter, and M. E. Hemler. 1991. In vitro and in vivo consequences of VLA-2 expression on rhabdomyosarcoma cells. Science (Wash. DC). 251:1600-1602.

41. Chan, B. M. C., M. J. Elices, E. Murphy, and M. E. Hemler. 1992. Adhe- 
sion to vascular cell adhesion molecule 1 and fibronectin: comparison of $\alpha 4 \beta 1$ (VLA-4) and $\alpha 4 \beta 7$ on the human cell line JY. J. Biol. Chem. 267:8366-8370.

42. Zylstra, S., F.-A. Chen, S. K. Ghosh, E. A. Repasky, U. Rao, H. Takita, and R. B. Bankert. 1986. Membrane-associated glycoprotein (gp 160) identified on human lung tumors by a monoclonal antibody. Cancer Res. 46:6446-6451.

43. Pischel, K. D., M. E. Hemler, C. Huang, H. G. Bluestein, and V. L. Woods. 1987. Use of the monoclonal antibody $12 \mathrm{~F} 1$ to characterize the differentiation antigen VLA-2. J. Immunol. 138:226-233.

44. Hemler, M. E., F. Sanchez-Madrid, T. J. Flotte, A. M. Krensky, S. J. Burakoff, A. K. Bahn, T. A. Springer, and Strominger. 1984. Glycoproteins of 210,000 and 130,000 m.w. on activated $T$ cells: cell distribution and antigenic relation to components on resting cells and T cell lines. J. Immunol. 132:3011 3018.

45. Akiyama, S. K., S. S. Yamada, W.-T. Chen, and K. M. Yamada. 1989 Analysis of fibronectin receptor function with monoclonal antibodies: roles in cell adhesion, migration, matrix assembly, and cytoskeletal organization. J. Cell Biol. 109:863-875.

46. Morimoto, C., N. L. Letvin, A. W. Boyd, M. Hagan, H. M. Brown, M. M. Kornacki, and S. F. Schlossman. 1985. The isolation and characterization of the human helper inducer T cell subset. J. Immunol. 134:3762-3769.

47. Hemler, M. E., C. F. Ware, and J. L. Strominger. 1983. Characterization of a novel differentiation antigen complex recognized by a monoclonal antibody (A-1A5): unique activation-specific molecular forms on stimulated T cells. $J$. Immunol. 131:334-330.

48. Kearney, J. F., A. Radbruch, B. Liesegang, and K. Rajewsky. 1979. A new mouse myeloma cell line that has lost immunoglobulin expression but permits the construction of antibody-secreting hybrid cell lines. J. Immunol. 123:15481550 .

49. Barnstable, C. J., W. F. Bodmer, G. Brown, G. Galfre, C. Milstein, A. F. Williams, and A. Ziegler. 1978. Production of monoclonal antibodies to Group A erythrocytes, HLA and other cell surface antigens-new tools for genetic analysis. Cell. 14:9-20.

50. Brodsky, F. M., and P. Parham. 1982. Monomorphic anti-HLA-A,B,C monoclonal antibodies detecting molecular subunits and combinatorial determinants. J. Immunol. 128:129-135.
51. Shepley, M. P., B. Sherry, and H. L. Weiner. 1988. Monoclonal antibody identification of a $100 \mathrm{kDa}$ membrane protein in HeLa cells and human spinal cord involved in poliovirus attachment. Proc. Natl. Acad. Sci. USA. 85:77437747.

52. Santoro, S. A. 1986. Identification of a 160,000 dalton platelet membrane protein that mediates the initial divalent cation-dependent adhesion of platelets to collagen. Cell. 46:913-920.

53. Corbi, A. L., L. J. Miller, K. O’Connor, R. S. Larson, and T. A. Springer. 1987. cDNA cloning and complete primary structure of the alpha subunit of a leukocyte adhesion glycoprotein, p150,95. EMBO (Eur. Mol. Biol. Organ.) J. 6:4023-5028.

54. Edwards, J. G., H. Hameed, and G. Campbell. 1988. Induction of fibroblast spreading by $\mathrm{Mn} 2+$ : a possible role for unusual binding sites for divalent cations in receptors for proteins containing Arg-Gly-Asp. J. Cell Sci. 89:507-513.

55. Staatz, W. D., K. F. Fok, M. M. Zutter, S. P. Adams, B. A. Rodriquez, and S. A. Santoro. 1991. Identification of a tetrapeptide recognition sequence for the $\alpha 2 \beta 1$ integrin in collagen. J. Biol. Chem. 266:7363-7367.

56. Vandenberg, P., A. Kern, A. Ries, L. Luckenbill-Edds, K. Mann, and K. Kühn. 1991. Characterization of a type IV collagen major cell binding site with affinity to the $\alpha 1 \beta 1$ and the $\alpha 2 \beta 1$ integrins. J. Cell Biol. 113:1475-1483.

57. Cardarelli, P. M., S. Yamagata, I. Taguchi, F. Gorcsan, S. L. Chiang, and T. Lobl. 1992. The collagen receptor $\alpha 2 \beta 1$, from MG-63 and HT1080 cells, interacts with a cyclic RGD peptide. J. Biol. Chem. 267:23159-23164.

58. Fox, G., N. R. Parry, P. V. Barnett, B. McGin, D. J. Rowlands, and F. Brown. 1989. The cell attachment site on foot-and-mouth disease virus includes the amino acid sequence RGD (arginine-glycine-aspartic acid). J. Gen. Virol. 70:625-637.

59. Roivainen, M., T. Hyypia, L. Piirainen, N. Kalkkinen, G. Stanway, and T. Hovi. 1991. RGD-dependent entry of coxsackievirus A9 into host cells and its bypass after cleavage of VP1 protein by intestinal proteases. J. Virol. 65:47354740

60. Acharya, R., E. Fry, D. Stuart, G. Fox, D. Rowlands, and F. Brown. 1989. The three-dimensional structure of foot-and-mouth disease virus at $2.9 \AA$ resolution. Nature (Lond.). 337:709-716. 